Research Article

\title{
Does Financial Development Hamper or Improve the Resource Curse? Analysis Based on the Panel Threshold Effect Model
}

\author{
ZhiQiang Sun $\mathbb{D}^{1,2}$ and ZeXiang Cai ${ }^{3}$ \\ ${ }^{1}$ Jinshen College, Nanjing Audit University, Jiangsu, Nanjing, China \\ ${ }^{2}$ College of Economics and Management, Nanjing University of Aeronautics and Astronautics, Jiangsu, Nanjing, China \\ ${ }^{3}$ School of Finance, Nanjing Audit University, Jiangsu, Nanjing, China
}

Correspondence should be addressed to ZhiQiang Sun; szq@nuaa.edu.cn

Received 31 March 2020; Revised 14 May 2020; Accepted 17 June 2020; Published 15 July 2020

Academic Editor: Kauko Leiviskä

Copyright (c) 2020 ZhiQiang Sun and ZeXiang Cai. This is an open access article distributed under the Creative Commons Attribution License, which permits unrestricted use, distribution, and reproduction in any medium, provided the original work is properly cited.

\begin{abstract}
This paper analyzes the "resource curse" and "financial threshold effect" that may exist in China and then uses the data from 30 provinces from 2004 to 2018 as research samples. We used linear regression and nondynamic panel threshold models to analyze the financial threshold effects of the "resource curse" hypothesis and the "resource curse" phenomenon. At the same time, we divided the level of financial development to verify the robustness of the research conclusions in this paper. The study found the following: (1) There is a certain correlation between the abundance of resources and economic growth. Whether this can be seen as a "curse" or a "blessing" of resources is significantly related to the degree of financial development. (2) Whether financial development can alleviate the "resource curse" depends on the degree of financial development. In the extremely scarce stage of financial resources, the resource endowment effect is obvious, and the level of economic development in resource-based regions will be higher than in other regions; when the level of financial development is low (financial resources are not scarce and have not reached a reasonable level), the phenomenon of the "resource curse" appears; when the level of financial development is highly developed, economic development benefits more from financial development, and the effects of resource endowment decline. Only when financial development is at a reasonable level can resource endowments effectively raise the level of economic development.
\end{abstract}

\section{Introduction}

Resource-oriented traditional economic growth theory holds that resource endowment is necessary for economic growth. Looking back on the course of modern economic development, Britain, the first county to experience an industrial revolution, had abundant resources such as coal and ore; the earliest areas of industrialization in Germany also appeared in the resource-intensive industrial area of Ruhr; the fact that the United States thrived in the late $19^{\text {th }}$ and early $20^{\text {th }}$ centuries is also closely related to wealthy resource extraction and production [1]. However, subsequent development practices have run counter to this, and countries and regions rich in resources often perform poorly. Whether it is Spain, Russia, or oil-rich countries such as Nigeria and
Venezuela, these countries have encountered development obstacles to varying degrees. On the contrary, Switzerland, Japan, Hong Kong, Taiwan, South Korea, Singapore, and other countries in the same period of time, under the condition of relatively scarce resources, are developing at a higher speed. After the 1950s, there was a lot of discussion about the negative correlation between natural resources and economic growth. Paypyrakis and Gerlagh [2] verified that the "resource curse phenomenon exists within the country" and therefore confirmed that the resource curse phenomenon exists. Auty [3] first proposed the "resource curse" proposition and summarized the negative correlation between resource abundance and economic growth as the "resource curse" effect and pointed out the development difficulties of resource-based economies. 
Abundant natural resources should be the source of momentum for economic growth, but the "traps" in economic development brought about by them have aroused much interest, especially regarding their theoretical mechanisms [4]. With the increasing amount of research on the transmission mechanism, there are fewer studies focused on solving the "resource curse." Why do resources cause development traps? Exploring the cause of the "resource curse" and overcoming resource problems have become an important issue for many resource-abundant countries [5].

China is a big, resource-rich country. Many resourcerich provinces and cities have contributed to the country's construction. However, with the exploitation of resources, many resource-based areas have encountered developmental obstacles. The questions of how to solve resource-based problems and promote resource-based areas are of great significance in terms of helping its transformation [6]. Evidence shows that resource abundance will also have a negative impact on the development of finance, but most studies do not mention the relationship between the "financial development level" and "resource abundance." When sorting through the development context of resourcerich countries, we found that not all resource-rich countries have fallen into a development trap. Compared with the tragic fate of some countries that have been "cursed by resources," other countries have achieved considerable development by virtue of their resource advantages. Research by Pendergas et al. [7] found that "resource countries that have gotten rid of the development trap have developed their financial development; on the contrary, resource countries that have suffered from curses often have very low levels of financial development." Is this a coincidence? Finance is the core of the modern economy, and an effective financial system has the important function of rationally allocating resources and vigorously promoting economic development. Can it also be applied to natural resources? On the basis of the financial perspective, this paper explores how the level of financial development affects the resources curse. On the basis of the panel data from 15 resource-based regions in China from 2004 to 2018, the Hansen threshold panel model and the quasi-irrelevant regression estimation (SUR) method were used to empirically analyze whether the financial development of resource-based regions would affect the resource curse.

The rest of the paper is organized as follows. Section 2 is a literature review, which mainly introduces the research of domestic and foreign scholars in this field, and provides a theoretical reference for the research of this article. Section 3 presents a detailed description of the method used in our study. Section 4 presents and discusses the results from the empirical analysis. Section 5 summarizes the conclusions and puts forward corresponding countermeasures and suggestions based on the empirical analysis results.

\section{Literature Review}

The introduction of the "resource curse" hypothesis has sparked widespread discussion in academia. Foreign researchers have previously studied the "resource curse" problem. Most of the research conclusions support the "resource curse" hypothesis, with the "resource curse" transmission mechanism being proposed from different dimensions studies [8-10]. Gylfason [11] systematically expounded on how the transmission mechanism of the "resource curse" affects economic growth and found that there are four transmission paths including "Dutch disease," rent-seeking, government decision-making errors, and human capital investment. Subsequently, a large number of scholars enlarged their assumptions on the analysis of the "resource curse" transmission mechanism. For example, Papyrakis and Gerlagh [2] found the existence of three "resource curse" transmission mechanisms: government corruption, foreign trade, and education investment. Wang and $\mathrm{Li}$ [12] used recent panel data at the provincial and municipal levels, and coal development intensity as a measurement index to test the "resource curse" effect of China's coal cities. The results show that the coal resources of the sample coal cities were significantly positively correlated with economic growth, which leads to the conclusion that the "resource curse" is not significant at the city level in China. Lu [13] believes that the root cause of a resource-rich country's long-term low performance in terms of developmental path is not based on the "curse" of abundant natural resources but should be attributed to the institutional conditions and the "path dependence" caused by changes. At the formal regulatory level, it is difficult for countries to benefit from an excess of knowledge and skills in a participation structure associated with resource property rights, which is further constrained by the dilemma of production capacity and operation, and management. In terms of constraints on the informal level, under the structure of a rent-seeking culture, fluctuations in the resource cycle weaken the system's reason, distort the incentive structure, and induce institutional changes. At the level of implementation path, the unpredictability of weak intertemporal commitments raises the transaction costs of the government entering into and fulfilling contracts with developmental enterprises. Peretto [14] expounded on the transmission mechanism of the "resource curse" from the perspective of technological innovation and found that there was a significant negative correlation between the abundance of resources and regional technological innovation capabilities. Bjorvatn et al. [15] found that rent resources and political resources are a significant factor for the "resource curse" and, thereafter, the transmission mechanism of political resources and political systems became the focus of research by experts and scholars [16]. However, as to whether it is the "resource blessing" or "resource curse," the academic community has always been undecided and has never come to reach a consensus. Studies by Song and Li [17] and Alexeev and Conrad [18] all challenge the "resource curse" hypothesis. They analyzed and found that the resource endowments of Russia, Canada, Norway, and other countries have a significant positive effect on economic growth. At the same time, they also pointed out that there is no direct evidence that rich natural resources have a destructive effect on economic growth. Haber and Menaldo [19], by excluding regional heterogeneity and time 
invariance, found through normative analysis that, in many cases, resources have a "blessing" effect.

Regarding the research of the "resource curse" phenomenon, foreign scholars mostly focus on qualitative analyses, while domestic scholars prefer quantitative analyses, and most of the conclusions confirm the "resource curse" hypothesis. Xu and Han [20] identified the "resource curse" problem in China from the perspective of the "Dutch disease" effect and the weakening of the system. Sun et al. [21] studied the relationship between natural resource dependence, public education investment, and human capital accumulation. They found that a dependence on natural resources and human capital accumulation were significantly negatively correlated. The crowding-out effect of natural resources on human capital only exists in the central and western regions of China. The government should use the income of the natural resources sector to increase investment in education to enhance local human capital. Jiang and Liu [22] used the "resource curse" hypothesis model to test the relationship between energy resource development and economic growth in Central Asia using panel data from five countries in Central Asia from 2000 to 2017. Studies have shown that, since the beginning of the $21^{\text {st }}$ century, there has been a significant positive relationship between energy resource development and economic growth in Central Asia, which excludes the hypothesis that the region's long-term dependence on energy resource development leads to a "resource curse." Sun et al. [23] believe that the government should adopt the method of transfer payment to promote regionally balanced development. Better economic and social policies will help transform wealth from natural resources to economic growth. Therefore, a "resource blessing" may occur instead of a "resource curse." Equitable distribution and high-quality education enhance human capital and thus promote economic growth, forcing a change from the current resource-driven model to a knowledgedriven model. Ma and Cheng [24] found the transformation mechanism of technological progress in the "resource curse" and "resource blessing" phenomena. According to their research, energy-based enterprises enjoy the "resource blessing" in the early stages of development. When the expansion of the enterprise reaches a certain threshold, the phenomenon of the "resource curse" appeared immediately. Wan and Wang [25] first studied the issues related to introducing social capital into the "resource curse" and found that the accelerated accumulation of social capital and technological innovation can cut off the transmission path of the "resource curse," and there is a threshold effect between them. Once the threshold is crossed, the "resource curse" is transformed into the "resource blessing." Therefore, measures such as encouraging technological innovation, increasing social capital cultivation, and improving government efficiency break the "resource curse" curse. Yan [26] used western China as a research object, analyzing the transition mechanism of policy thresholds, and the "resource curse" issue from the perspective of spatial value. He believes that since the Silk Road Economic Belt was jointly constructed, the "resource curse" has slowed down in western regions, and the "resource blessing" effect has increased.
In summary, in the research of the "resource curse" hypothesis, scholars mostly analyze the "resource curse" from the perspective of resource input, government functions, and technological innovation. Few scholars pay attention to financial development in the "resource curse" role in question. Some studies have inspired us; for example, Badeeb and Lean [27] believe that the financial system can bring rental income to natural resources. Although the authors did not perform a specific analysis at the theoretical or empirical level, it can still be used to highlight how the level of financial development is an important factor in the "resource curse." Yue and Zhang [28] explored the relationship between natural resource abundance and economic growth at different stages of financial development. Their research shows that, in China, there is a significant nonlinear relationship between resource abundance and economic growth, and only if the level of financial development is reasonable can the "resource curse" be turned into the "resource blessing." However, they only discussed the transmission mechanism on the theoretical level, and thus, an empirical level analysis is still lacking. More importantly, there is a lack of discussion on the formal financial market. It is undeniable that China has a "resource curse" problem. To explore whether financial development can effectively solve China's "resource curse" problem, it is necessary to explore whether financial development is an important transmission mechanism of the "resource curse" affecting economic growth.

\section{Method}

3.1. Panel Threshold Model. The threshold effect refers to the phenomenon of when one economic parameter reaches a certain value, another economic parameter suddenly changes to other forms of development; the critical value of this explanatory variable is the threshold value [29].

3.1.1. Model Settings. Hansen [30] defined the basic form of the "threshold regression" model as

$$
\begin{aligned}
& y_{i}=\theta_{1}^{\prime} x_{i}+e_{i}, \quad q_{i} \leq \gamma, \\
& y_{i}=\theta_{2}^{\prime} x_{i}+e_{i}, \quad q_{i}>\gamma,
\end{aligned}
$$

where $x_{i}$ as an explanatory variable is an $m$-dimensional column vector and $q_{i}$ is a "threshold variable." Hansen [30] showed that the threshold variable can be either a regression element in the explanatory variable $x_{i}$ or an independent threshold variable, and according to the "threshold value" $\gamma$, samples can be divided into "two regimes."

When combining the forms of equations (1) and (2) into a single form, first, one needs to define a dummy variable $d_{i}(\gamma)=\left\{q_{i} \leq \gamma\right\}$ and let $x_{i}(\gamma)=x_{i} d_{i}(\gamma)$. Therefore, equations (1) and (2) can be written as

$$
y_{i}=\theta^{\prime} x_{i}+\delta_{n}^{\prime} x_{i}(\gamma)+e_{i}
$$

Through this method of adding dummy variables, we can see that $\theta=\theta_{2}$ and $\delta_{n}=\theta_{2}-\theta_{1}$. Then, we can rewrite equation (3) into a matrix form: 


$$
Y=X \theta+X_{\gamma} \delta_{n}+e .
$$

The regression parameters in the model are $\left(\theta, \delta_{n}, \gamma\right)$. When $\gamma$ is given, $\theta$ and $\delta_{n}$ in equation (4) have a linear relationship. Therefore, according to the conditional least squares estimation method, using $X_{\gamma}^{*}=\left[\begin{array}{ll}X & X_{r}\end{array}\right]$ for regression on $Y$, the corresponding residual sum of squares function is as follows:

$$
S_{n}(\gamma)=S_{n}(\theta(\gamma), \delta(\gamma), \gamma)=Y^{\prime} Y-Y^{\prime} X_{\gamma}^{*}\left(X_{\gamma}^{*^{\prime}} X_{\gamma}^{*}\right)^{-1} X_{\gamma}^{*^{\prime}} Y .
$$

The estimated threshold value is used to minimize $S_{n}(\gamma)$. It is defined as

$$
\widehat{\gamma}=\arg \min _{\gamma \in \Gamma_{n}} S_{n}(\gamma),
$$

where $\Gamma_{n}=\Gamma \cap\left\{q_{1}, \ldots, q_{n}\right\}$. Hansen [30] took each observation in the threshold variable as a possible threshold and determined the observation value that suits equation (6) as the threshold. After the threshold value is determined, other parameter values can be determined accordingly.

3.2. Significance Test. The purpose of a significance test is to test whether the model estimation parameters of two groups of samples divided by threshold values are significantly different. Therefore, the null hypothesis in which no threshold exists is $H 0: \theta 1=\theta 2$. The Lagrange Multiplier (LM) statistics are constructed as follows:

$$
L=n \frac{S_{0}-S_{n}(\widehat{\gamma})}{S_{n}(\widehat{\gamma})},
$$

where $S_{0}$ is the sum of squared residuals under the null hypothesis. Because the LM statistics do not obey the standard distribution, Hansen [31] proposed the idea of obtaining the asymptotic distribution by "Bootstrap" and then obtained the corresponding probability $P$ value, known as the Bootstrap $P$ value. The basic idea of this method is that, under the premise of given explanatory variables and threshold values, a simulation generates a set of dependent variable sequences and makes it obey $N\left(0, \hat{e}^{2}\right)$, where $\hat{e}$ is the residual of the item in equation (4). For each self-sampling sample, a simulated LM statistic can be calculated. This process was repeated 1000 times, and Hansen [31] showed that the $P$ value estimated by the "Bootstrap method" was equal to the number of times the LM statistics generated by the simulation exceeded that of the formula (equation (7)), which was expressed as a percentage of the total number of simulations. The Bootstrap $P$ value here is similar to the companion probability $P$ value obtained by ordinary measurement methods. For example, when the Bootstrap $P$ value is less than 0.01 , it means that the LM test has passed a significance level of $1 \%$, and so on.

3.3. Confidence Interval. When it is determined that there is a "threshold effect" for a certain variable, the confidence interval of its threshold value needs to be further determined. The null hypothesis H0: Test, "Likelihood Ratio Statistic" can be expressed as

$$
\operatorname{LR}_{n}(\gamma)=n \frac{S_{n}(\gamma)-S_{n}(\widehat{\gamma})}{S_{n}(\widehat{\gamma})}
$$

Hansen [32] believes that when $\operatorname{LR}_{n} \quad(\gamma) \leq c$ $(\alpha)=-2 \ln (1-\alpha)$, the null hypothesis cannot be rejected $(\alpha$ indicates the significance level). Here, $c(\alpha)$ equals 7.35 at a 95\% confidence level.

The above test process is a test process with only one threshold. In order to determine whether there are two thresholds or more, we should check whether there are two thresholds. Rejecting $L$ means that at least one threshold exists. We can assume that we have estimated $\widehat{\gamma}_{1}$ and then start looking for a second threshold $\widehat{\gamma}_{2}$. After determining that there are two thresholds, the third threshold is sought, using the same method as before, until we cannot reject the null hypothesis.

\section{Results Analysis}

\subsection{Variable Selection and Data Description}

4.1.1. Sample Selection. Regarding the feasibility of the study, we used data from 30 provinces in China (excluding Tibet Autonomous Region and Hong Kong, Macao, and Taiwan) from 2004 to 2018 as the research sample, which constitutes a balanced panel of 450 observations. The data mainly come from the National Bureau of Statistics, the statistical yearbooks of the provinces, the WIND database (WIND), and the Guo Tai'an database (CSMAR).

\subsubsection{Explained Variable}

(1) The Level of Development of the Real Economy (y). After the outbreak of the financial crisis, the US Federal Reserve frequently used the term real economy and defined it as a part other than the financial and real estate industries, and other domestic scholars also refer to industries other than finance and real estate as the real economy in their research. The measurement method is to subtract GDP from the output value of the financial industry and real estate industry. This paper draws on the practice of scholars and also uses this method to measure the level of real economy development in each region, expressed as $y$.

\subsubsection{Explanatory Variables}

(1) Natural Resource Abundance (res). To test the "resource curse" hypothesis, we first estimated the abundance of resources in each region. Some scholars use the total wages of employees in extractive industries/total wages of regional employees, the ratio of investment in extractive industry construction to GDP, and the value of energy industrial output/total industrial output as indicators of the abundance of natural resources. Because of the large regional differences in energy distribution, these can better reflect the natural resource endowment characteristics of a region. Therefore, 
this paper uses energy abundance to indicate the level of regional natural resource endowment. Here, we draw on various research methods to measure regional natural resource abundance:

$$
\text { res }=\frac{\omega_{1} * \operatorname{coal}+\omega_{2} \text { oil }+\omega_{3} \text { nature gas }}{\text { coal }+ \text { oil }+ \text { nature gas }} .
$$

Among them, $\omega 1, \omega 2$, and $\omega 3$ represent the standard coal conversion reference of raw coal, crude oil, and natural gas, respectively (the reference coefficients of raw coal, crude oil, and natural gas to standard coal converted by China Energy Statistical Yearbook 2013 are $0.7143,1.4286$, and 1.33); coal, oil, and natural gas represent proven reserves of coal, oil, and natural gas.

(2) Physical Capital Investment (inv). This refers to the use of the fixed asset investment amount/the level of development of the real economy $(y)$. In order to facilitate the subsequent empirical analysis of the relationship between the real estate market, finance, and the real economy, we divided the indicator inv into the following groups: (fixed asset investment amount minus real estate development investment amount)/ the level of development of the real economy $(y)$ as inv1; and the amount of real estate development investment/the level of development of the real economy $(y)$ as inv2; inv2 represents the real estate investment in each region.

(3) Human Capital Investment (edu). In order to facilitate analysis and data collection, we borrowed from the calculation methods of scholars such as Zhang and Zhang [33]. Herein, it is measured by the average years of education.

(4) Scientific and Technological Innovation (tech). This refers to the three scientific and technological expenses/y as an index to measure scientific and technological innovation, where the three scientific and technological expenses refer to the new product trial production fees, intermediate trial fees, and subsidies for major scientific research projects established by the state to support the development of scientific and technological undertakings.

(5) Degree of Openness (open). In this paper, we used the total value of import and export trade/the level of development of the real economy $(y)$ [34].

(6) Corruption (cor). Rent-seeking and corruption are one of the ways to "curse" resources, so this article adds a corruption variable cor, which is measured by the number of crimes (corruption, bribery, and misconduct) per 10,000 public officials.

4.1.4. Threshold Variables. The threshold variable to be verified in this article is the financial development (fin). The selection of the variable of finance development was done considering that, in China, financial institutions have a central bank as the core and a commercial bank as the main body, i.e., a coexisting financial system. Therefore, given the characteristics of this bank-led financial system, the financial development variable should be a bank-related indicator. At the same time, we know that corporate activities are closely related to deposits and loans, and financial institutions have significant differences in deposits and loans. Therefore, we chose "ratio of loans to regional GDP" as the index of financial development variables.

4.2. Model Construction. In order to clarify whether financial development affects the relationship between natural resources and the real economy, this paper uses the Hansen threshold model for the empirical test. The basic idea of the single threshold regression in this article is that there is a threshold $\gamma$ for the financial development level fin in the model. For fin $\geq \gamma$ and fin $<\gamma$, the relationship between natural resources and the growth of the real economy has obvious differences. The single threshold panel model is set as follows:

$$
y_{i t}=\mu_{i}+\alpha X_{i t}+\beta_{1} \operatorname{res}_{i t}\left(\operatorname{fin}_{i t}<\gamma\right)+\beta_{2} \operatorname{res}_{i t}\left(\operatorname{fin}_{i t} \geq \gamma\right)+\varepsilon_{i t},
$$

where $i$ represents each region; $t$ represents the year; the interpreted variable $y_{i t}$ is the growth rate of the real economy; res ${ }_{i t}$ represents the abundance of natural resources; $X_{i t}$ is the main variable affecting the growth of the real economy; $\gamma$ is an unknown threshold; $I(\bullet)$ is indicator function; $\beta_{1}$ and $\beta_{2}$ denote the influence coefficients of the threshold variable fin on the growth of the real economy under the conditions of $\operatorname{fin}_{i t} \geq \gamma$ and fin $_{i t}<\gamma ; \mu_{i}$ is the regional individual effect; $\alpha$ is the parameter to be estimated; and $\varepsilon_{i t}$ is a random error term. Multiple thresholds may appear during the research. The triple thresholds are used as an example to explain the multiple thresholds model. The model of the triple threshold panel is set as follows:

$$
\begin{aligned}
y_{i t}= & \mu_{i}+\alpha X_{i t}+\beta_{1} \operatorname{res}_{i t}\left(\operatorname{fin}_{i t}<\gamma_{1}\right)+\beta_{2} \operatorname{res}_{i t}\left(\gamma_{1}<\operatorname{fin}_{i t} \leq \gamma_{2}\right) \\
& +\beta_{3} \operatorname{res}_{i t}\left(\gamma_{2}<\operatorname{fin}_{i t} \leq \gamma_{3}\right)+\beta_{4} \operatorname{res}_{i t}\left(\operatorname{fin}_{i t}>\gamma_{3}\right)+\varepsilon_{i t} .
\end{aligned}
$$

First, the threshold value is estimated (by choosing the fin value that minimizes the sum of the squared residuals of the model as the threshold value); then the coefficient values of other variables are estimated. Thereafter, a significance test on the threshold value is performed to test whether the threshold effect exists, and after determining the number of thresholds, a confidence interval for $\gamma$ to test the truth of the threshold effect is constructed.

\subsection{Empirical Results Analysis}

4.3.1. Descriptive Statistical Analysis. Table 1 shows the descriptive statistics of the variables. From the perspective of the explanatory variables, the mean value of $y$ is 1.133 , the standard deviation is 0.552 , and the range is 2.697 . The standard deviation is the sum of the square of the difference between the data and the average. The smaller the standard deviation, the more stable the data. From the descriptive statistics, the standard deviation is small, indicating that the selected data $(y)$ has a good level of stability. Therefore, the 
TABLE 1: Variable descriptive statistics.

\begin{tabular}{lccccc}
\hline Variable & Number of samples & Mean & Standard deviation & Minimum value & Maximum value \\
\hline$y$ & 450 & 1.133 & 0.552 & -0.298 & 0 \\
res & 450 & 3.191 & 3.656 & 1.033 & 2.399 \\
fin & 450 & 2.554 & 0.543 & 2.763 & 4.021 \\
inv & 450 & 3.887 & 0.502 & 0.697 & 4.882 \\
edu & 450 & 1.776 & 0.548 & 0.612 & 3.213 \\
tech & 450 & 2.109 & 0.631 & 0.591 & 3.229 \\
cor & 450 & 1.032 & 0.598 & 0.339 & 3.218 \\
open & 450 & 1.663 & 0.661 & 2.212 \\
\hline
\end{tabular}

empirical test mainly uses $y$ as the explanatory variable for analysis. In addition, it can also be seen that there are large differences in the level of regional economic development in China. From the perspective of explanatory variables, the average of the abundance of natural resources is 3.191, the standard deviation is 3.656 , and the range is 15.782 , which indicates that there are great differences in resource endowments between regions in China. The average of financial development is 2.554 , the standard deviation is 0.543 , and the range is 2.988 , indicating that there are significant differences in financial development between regions in China. In terms of control variables, the standard deviations of inv, edu, open, cor, and tech are all greater than 0.5 , indicating that regional differences are significant.

4.3.2. Empirical Results Analysis. The paper examines the impact of the level of financial development on the relationship between natural resources and the real economy, verifies whether there is an impact, and conducts an empirical analysis of its impact path.

(1) Test and Analysis of the "Financial Threshold effect" Hypothesis. The threshold test results in Table 2 show that the $F$ values of the single threshold test are 33.998 and the corresponding $P$ values are 0.001 , indicating that the model has a threshold effect. The $F$ value of the double threshold model test is 8.332, and the corresponding $P$ values are 0.002 , indicating that the model may have two or more thresholds. The triple threshold test results show that there is a third threshold, indicating a triple threshold effect.

(2) Threshold Estimation Regression Results. According to the threshold test results, there is a triple threshold effect, so the equation is established as follows:

$$
\begin{aligned}
y_{i t}= & \mu_{i}+\alpha X_{i t}+\beta_{1} \operatorname{res}_{i t}\left(\operatorname{fin}_{i t}<\gamma_{1}\right)+\beta_{2} \operatorname{res}_{i t}\left(\gamma_{1}<\operatorname{fin}_{i t} \leq \gamma_{2}\right) \\
& +\beta_{3} \operatorname{res}_{i t}\left(\gamma_{2}<\operatorname{fin}_{i t} \leq \gamma_{3}\right)+\beta_{4} \operatorname{res}_{i t}\left(\operatorname{fin}_{i t}>\gamma_{3}\right)+\beta_{5} \operatorname{inv}_{i t} \\
& +\beta_{6} \text { edu }+\beta_{7} \operatorname{tech}_{i t}+\beta_{8} \operatorname{cor}_{i t}+\beta_{9} \operatorname{open}_{i t}+\varepsilon_{i t} .
\end{aligned}
$$

In this paper, we use the uncorrelated regression estimation (SUR) method to perform the test. The results are presented in Table 3 [35].

From the regression results in Table 3, when the level of financial development is low (fin $\leq 2.431$ ), the regression coefficient of res is a significant positive number, indicating that, in the lower level stage of financial development, the
TABLE 2: Threshold effect test results.

\begin{tabular}{lcc}
\hline Test type & Statistics & Test result \\
\hline & $\gamma$ & 2.663 \\
Single threshold test & 95\% confidence interval & $(2.656,2.692)$ \\
& $F$ value & 33.998 \\
& $P$ value & 0.001 \\
\hline & $\Gamma_{1}$ & 2.445 \\
& $95 \%$ confidence interval & $(1.345,3.223)$ \\
Double threshold test & $\Gamma_{2}$ & 2.625 \\
& $95 \%$ confidence interval & $(2.625,2.676)$ \\
& $F$ value & 8.332 \\
& $P$ value & 0.002 \\
\hline Triple threshold test & $\Gamma_{3}$ & 2.431 \\
& $95 \%$ confidence interval & $(2.431,2.431)$ \\
& $F$ value & 13.921 \\
& $P$ value & 0.004 \\
\hline \multirow{4}{*}{ Basic information } & Number of iterations & 450 \\
& Search points & 150 \\
& Time dimension & 15 \\
& Number of sections & 30 \\
& Number of samples & 450 \\
\hline
\end{tabular}

TABle 3: Threshold estimation regression results.

\begin{tabular}{lcc}
\hline Variable & Coefficient & $P$ value \\
\hline res $($ fin $<2.431)$ & $0.027^{* * *}$ & 0.002 \\
res $(2.431<$ fin $\leq 2.445$ & $-0.018^{* * *}$ & 0.001 \\
res $(2.445<$ fin $\leq 2.625)$ & $0.033^{* * *}$ & 0.000 \\
res $($ fin $>2.625)$ & -0.019 & 0.334 \\
inv & 0.088 & 0.238 \\
edu & $0.012^{* * *}$ & 0.004 \\
tech & $0.134^{* * *}$ & 0.001 \\
cor & $-0.223^{* * *}$ & 0.000 \\
open & 0.033 & 0.349 \\
\hline
\end{tabular}

Note. ${ }^{* * *}$ Significant under $1 \%$ condition.

regions with higher levels of resource abundance have a higher level of economic development. When the level of financial development crosses the first threshold but does not cross the second threshold $(2.431<$ fin $\leq 2.445)$, the regression coefficient of res is a significant negative number, which indicates that, at this stage, the abundance of resources cannot significantly promote economic development, and the "resource curse" phenomenon has occurred. When the level of financial development is high $(2.445<$ fin $\leq 2.625)$, the regression coefficient of res is a significant positive number, indicating that, during periods 
of high financial development, the relationship between resource abundance and the level of economic development is positive, and this stage has changed from "resource curse" to "resource blessing." When finance is in the developed stage (fin $>2$. 625), the regression coefficient of res is an insignificant negative number, indicating that there is an insignificant inverse correlation between economic growth rate and resource abundance. Although the relationship between economic development and resource abundance is not significant at the stage of financial development, the regression coefficient is negative, indicating that there may be a "resource curse" phenomenon.

To sum up, first, when the level of financial development is not high, economic growth is mainly affected by the abundance of resources. The economic development level of resource-based regions at this stage is higher than the economic development level of non-resource-based regions, and thus, the "resource blessing" effect occurs [36, 37]. Second, when finance is overdeveloped, the restriction of resource endowment on economic growth decreases, and the impact of resource endowment on economic growth can even be ignored. We think there are three possible reasons: (1) The transformation effect of economic development. Economic development is accompanied by the transformation and upgrading of the industrial structure. Thus, traditional industrial enterprises that depend on natural resources for survival gradually withdraw from the market as technology changes, nonrenewable resource development and use costs increase, and market demand changes. In addition, the contribution of traditional resource-based industrial enterprises towards economic growth declines. (2) The "Matthew effect" regarding capital profit-seeking can be described as follows [38, 39]: with the development of finance, financial capital is sufficient, and funds are invested in emerging industries. At the same time, when the level of financial development increases, a virtual economy is also generated, and its high return rate inevitably prompts financial institutions to invest a lot of funds in the virtual economy market, which not only promotes the generation of financial bubbles, but also leads to difficulties in financing the real economy, thereby inhibiting economic growth. (3) The substitution effect of financial development. During the period of excessive financial prosperity, the role of financial development in promoting economic growth makes up for the restraining effect of resource endowments on economic growth. In other words, in the highly developed financial stage, even if there is a "resource curse" phenomenon, it does not show. The regression results also show that the level of financial development can promote the healthy development of the economy only in a reasonable range. At this time, the input of natural resources, including the input of physical capital, will reach the highest utilization rate, which can significantly promote economic growth.

\section{Conclusions and Recommendations}

5.1. Conclusions. Aiming at the "resource curse" hypothesis, this article first derived the "resource curse" and "financial threshold effect" that may exist in China. Then, using data from 30 provinces from 2004 to 2018 as a research sample, linear regression and the non-dynamic panel threshold model were used to analyze the financial threshold effect in terms of the "resource curse" hypothesis. At the same time, the paper divides the level of financial development to verify the robustness of the conclusions of this paper. The conclusions are as follows:

(1) The research in this paper shows that there is a certain correlation between the degree of resource abundance and economic growth. Whether it is a "curse" of resources or a "blessing" of resources is significantly related to the degree of financial development.

(2) In areas where the level of financial development is low, the regions with higher resource abundance are more dependent on resources for economic development, and they can promote economic growth through resource development.

When the level of financial development is further improved, the degree of resource abundance cannot significantly promote economic development, resulting in a "resource curse" phenomenon. As the level of financial development increases, the further dependence on resources reduces the efficiency of resource utilization and hinders economic growth; thus, there is a "curse" of resources.

When the level of financial development is high, there is a positive correlation between the level of resource abundance and the level of economic development during the period of high levels of financial development. The effects of economic transformation at this stage are greater than the negative effects of resource development. Thus, the "resource curse" turns into a "resource blessing."

When finance is in a developed stage, there is an insignificant reverse correlation between the economic growth rate and resource abundance. Although the relationship between economic development and resource abundance in the financially advanced stage is not significant, the regression coefficient is negative, indicating that there may be a "resource curse" phenomenon.

5.2. Recommendations. It can be seen that the level of financial development can promote the healthy development of the economy only within a reasonable range. At this time, the input of natural resources, including the input of physical capital, will reach the highest utilization rate, which can significantly promote economic growth. At present, most of China's traditional resource-based provinces are located in less developed regions, and the level of financial development in these regions is generally low. Therefore, the "resource curse" phenomenon is common. The research in this article demonstrates that, in order to solve the "resource curse" problem and improve the level of resource-based regional economic development, we need to make financial decisions, such as promoting the development of the financial industry, improving the ability and level of financial services related to the real economy, and controlling financial capital flow. The details are as follows: 
(1) Reasonably adjust the central and local financial resource allocation and responsibilities, and improve the public financial system. The increase in local government financial power and the increase in general power are the reasons for the increase in extra-budgetary land fiscal revenue and the rapid development of the virtual economy. Therefore, we must improve the public financial system, rationally adjust the central and local financial resources and responsibilities, and improve the central and local financial power. Thus, the mechanism of equilibrating the powers associated with different affairs fundamentally eliminates the inherent incentives for local governments to be enthusiastic about land finance and to promote the rapid development of the virtual economy. As regards policy regulation on the real estate market [40], fiscal decentralization promotes the development of the real estate industry, causing a large amount of financial capital to flow into the real estate market. This causes excessive short-term prosperity, which leads to excessive speculative demand for investment, while the supply lags, causing short-term supply shortages and rising housing prices. Deviating from its own value creates a real estate bubble, so it is necessary to limit the overdevelopment of the real estate industry (in addition to policy housing such as affordable housing), reduce its virtual component, and prevent the bubble from bursting into crisis [41].

(2) Unblock the channels for finance to enter the real economy. First, develop city commercial banks, village and town banks, financial investment holding group companies, and financial leasing companies, and continuously improve the financial institution system [42]. Second, we must develop a multi-level capital market system, continuously improve the stock market, securities market, expand the insurance market service area, gradually establish regional energy trading spots and future markets, actively develop derivatives trading markets, promote the continued expansion of regional equity markets, and expand the financing channels of physical enterprises [43]. Third, we must guide the healthy development of private finance. This can be done by establishing loan registration service centers in areas where private capital is active to promote the "sunshine" of private financing, gradually incorporating private financing subjects into the credit reporting system to reduce credit risk, establishing and improving a private financing monitoring system to resolutely curb deception and illegal fundraising to guide private capital to serve small- and medium-sized private enterprises. Then, financial institutions should change the single evaluation criteria of performance as the king, include serving small- and medium-sized microenterprise entities, serve the development of the local real economy into the evaluation system, and reasonably guide the flow of financial capital [44]. Finally, we should step up our efforts to crack down on illegal behavior in the financial market, establish and improve local financial supervision systems, and reasonably protect the real economy.

(3) The reason why the massive inflow of resource-based regional capital into the virtual economy is important is that the operating environment of the real economy is not good, the cost of money is high, the profits are thin, and the investment channels are narrow. On this basis, resource industries in resourcebased areas should be de-capacified, and enterprises should accelerate transformation, promote efficient and clean development and utilization of resources, and encourage the development of high-tech industries and strategic emerging industries.

\section{Limitation and Outlook}

On the basis of the previous research results, this paper uses the panel threshold model to analyze the impact of financial development on the "resource curse" and "resource blessing" phenomena. As a result of the limitations of the author's academic level and ability, and the difficulty of data collection, this study has various limitations. For example, financial development is a long-term process, and whether it produces a "blessing" or "curse" should be studied over a longer period of time to investigate the entire life cycle of natural resource development and utilization. Otherwise, only a local conclusion can be drawn. For reasons pertaining to the data, this article could not investigate the impact of financial development over a longer period. This will be the direction of future research.

It is difficult to obtain ideal sample data, which inevitably leads to limitations related to the research conclusion. We believe that, with the further deepening of the related research, and the further enrichment of economic statistics, academia will surely draw more detailed and reliable research results to make up and correct the deficiencies and errors in this article. Finally, the "resource blessing" and "resource curse" phenomena may be affected by the financial development of neighboring regions, as well as other spatial effects. The authors will consider the effects of spatial factors in future research in the hope of enriching the existing research results.

\section{Data Availability}

All data, models, and codes generated or used during the study are included within the submitted article.

\section{Conflicts of Interest}

The authors declare no conflicts of interest.

\section{References}

[1] S. Tiba and M. Frikha, "The controversy of the resource curse and the environment in the SDGs background: the African context," Resources Policy, vol. 62, no. 8, pp. 437-452, 2019. 
[2] E. Papyrakis and R. Gerlagh, "The resource curse hypothesis and its transmission channels," Journal of Comparative Economics, vol. 32, no. 1, pp. 181-193, 2004.

[3] R. M. Auty, "Industrial policy reform in six large newly industrializing countries: the resource curse thesis," World Development, vol. 22, no. 1, pp. 11-26, 1994.

[4] T. T. Deng, Y. R. Liu, and M. L. Ma, "Tourism industry dependence and total factor productivity growth: a test based on the "resource curse" hypothesis," Tourism Science, vol. 33, no. 1, pp. 1-17, 2019.

[5] M. J. Vijge, R. Metcalfe, L. Wallbott, and C. Oberlack, "Transforming institutional quality in resource curse contexts: the extractive industries transparency initiative in Myanmar," Resources Policy, vol. 61, no. 6, pp. 200-209, 2019.

[6] P. C. Wang and B. X. Sun, "Influence of energy endowment and trade opening on resource green utilization efficiency," Journal of Dalian University of Technology: Social Science Edition, vol. 2, pp. 9-16, 2019.

[7] S. M. Pendergast, J. A. Clarke, and G. C. Van Kooten, "Corruption, development and the curse of natural resources," Canadian Journal of Political Science, vol. 44, no. 2 , pp. 411-437, 2011.

[8] J. D. Sachs and A. M. Warner, "Natural resource abundance and economic growth," NBER Working Papers, vol. 81, no. 4, pp. 496-502, 1995.

[9] J.-P. C. Stijns, "Natural resource abundance and economic growth revisited," Resources Policy, vol. 30, no. 2, pp. 107-130, 2005.

[10] J. G. Weber, "A decade of natural gas development: the makings of a resource curse?" Resource and Energy Economics, vol. 37, no. 3, pp. 168-183, 2014.

[11] T. Gylfason, "Natural resources and economic growth: what is the connection?" Social Science Electronic Publishing, vol. 53, no. 8, pp. 48-66, 2001.

[12] B. Q. Wang and J. Y. Li, "An empirical study on the "resource curse" effect of China's coal cities," Statistics and Decision, vol. 10, pp. 121-125, 2019.

[13] S. H. Lu, "Paradox of the development of resource countries from the perspective of institutional transmission: "resource curse" and "path dependence"” Academic Exploration, vol. 8, pp. 59-66, 2019.

[14] P. F. Peretto, "Resource abundance, growth and welfare: a schumpeterian perspective," Journal of Development Economics, vol. 97, no. 1, pp. 142-155, 2012.

[15] K. Bjorvatn, M. R. Farzanegan, and F. Schneider, "Resource curse and power balance: evidence from oil-rich countries," World Development, vol. 40, no. 7, pp. 1308-1316, 2012.

[16] J. A. Robinson, R. Torvik, and T. Verdier, "Political foundations of the resource curse: a simplification and a comment," Journal of Development Economics, vol. 79, no. 2, pp. 194-198, 2006.

[17] J. Song and W. H. Li, "Countermeasures for the industrial transformation of resource-based cities in heilongjiang province: based on the discussion of "resource curse" areas," Commercial Economy, vol. 9, pp. 7-8, 2019.

[18] M. Alexeev and R. Conrad, "The elusive curse of oil," Review of Economics and Statistics, vol. 91, no. 3, pp. 586-598, 2009.

[19] S. Haber and V. Menaldo, "Do natural resources fuel authoritarianism? a reappraisal of the resource curse," American Political Science Review, vol. 105, no. 1, pp. 1-26, 2011.

[20] K. N. Xu and J. Han, "The resource curse effect of China's regional economy: another interpretation of regional disparity," The Economist, vol. 6, pp. 96-102, 2005.
[21] H.-P. Sun, W.-F. Sun, Y. Geng, and Y.-S. Kong, "Natural resource dependence, public education investment, and human capital accumulation," Petroleum Science, vol. 15, no. 3, pp. 657-665, 2018.

[22] A. Y. Jiang and B. Liu, "Research on resource development and economic growth in central Asia-an empirical analysis based on the "resource curse" hypothesis," Exploration of Economic Problems, vol. 5, pp. 34-43, 2019.

[23] H.-P. Sun, W.-F. Sun, Y. Geng, X. Yang, and B. K. Edziah, "How does natural resource dependence affect public education spending?" Environmental Science and Pollution Research, vol. 26, no. 4, pp. 3666-3674, 2019.

[24] Y. Ma and D. J. Cheng, "The gospel of resources or the curse of resources: an empirical study based on the threshold panel model," Finance and Trade Research, vol. 1, pp. 13-25, 2017.

[25] J. X. Wan and S. Y. Wang, "Can social capital and technological innovation break the resource curse ?: a study based on the panel threshold effect," Economic Research, vol. 12, pp. 66-89, 2016.

[26] L. Yan, "Serving the west of the silk road economic belt: understanding the curse of resources and understanding the space value," Journal of Lanzhou University, vol. 2, pp. 127138, 2017.

[27] R. A. Badeeb and H. H. Lean, "Financial development, oil dependence and economic growth," Studies in Economics and Finance, vol. 34, no. 2, pp. 281-298, 2017.

[28] H. Yue and H. J. Zhang, "Financial development, resource curse and economic growth," Journal of East China Normal University, vol. 6, pp. 138-150, 2019.

[29] D. Y. Peng, C. Liu, and Y. F. Zhou, "Study on the threshold effect of the impact of urbanization development on haze pollution in the yangtze river economic belt: based on the perspective of residents' consumption level," Finance and Economy, vol. 8, pp. 36-42, 2015.

[30] B. E. Hansen, "Threshold effects in non-dynamic panels: estimation, testing, and inference," Journal of Econometrics, vol. 93, no. 2, pp. 345-368, 1999.

[31] B. E. Hansen, "Inference when a nuisance parameter is not identified under the null hypothesis," Econometrica, vol. 64, no. 2, pp. 413-430, 1996.

[32] B. E. Hansen, "Sample splitting and threshold estimation," Econometrica, vol. 68, no. 3, pp. 575-603, 2000.

[33] C. S. Zhang and B. Z. Zhang, "The mystery of the decline in China's industrial investment rate: from the perspective of economic finance," Economic Research, vol. 12, pp. 34-48, 2016.

[34] G. Nahom, "FDI technology spillovers in the mining industry: lessons from South Africa's mining sector," Resources Policy, vol. 62, pp. 463-471, 2019.

[35] K. Lahiri and P. Schmidt, "On the estimation of triangular structural systems," Econometrica, vol. 46, no. 5, pp. 12171221, 1978.

[36] X. J. Yao and J. Dang, "Research on the influence of natural resources on economic growth from the perspective of industrial structure," Journal of Xi'an Shiyou University, vol. 6, pp. 21-29, 2019.

[37] Y. P. Chen, J. He, and C. L. Zhong, “"Gospel” or "curse": research on the asymmetric impact of resource abundance on china's regional economic growth," Macroeconomic Research, vol. 11, pp. 139-152, 2018.

[38] T. E. Ba, "Analysis of the "matthew effect" of financial agglomeration on the distribution of regional financial resources," Journal of Inner Mongolia University for Nationalities, vol. 43, no. 1, pp. 85-89, 2017. 
[39] W. Y. Han, "An empirical analysis of the efficiency of financial resource agglomeration in economic growth in provincial regions," Business Times, vol. 5, pp. 160-162, 2016.

[40] X. L. He and Y. Ye, "Research on the relationship between environmental pollution and regional economic growth based on the perspective of resource curse," Journal of Hubei University of Economics, vol. 4, pp. 20-31, 2019.

[41] J. Chen, Y. P. Liu, and L. J. Wang, "Research on coupling coordination development for photovoltaic agriculture system in China," Sustainability, vol. 11, no. 4, p. 1065, 2019.

[42] L. Feng, "Analysis on the transformation and innovation of organizational capacity building from the perspective of resource curse," Leadership Science, vol. 12, pp. 31-34, 2019.

[43] Z. X. Tan and G. N. Sun, "The foundation of high-quality tourism development: an analysis of the gospel of tourism resources," Social Scientist, vol. 5, pp. 108-115, 2019.

[44] L. J. Wang, Y. Wang, and J. Chen, "Assessment of the ecological niche of photovoltaic agriculture in China," Sustainability, vol. 11, no. 8, p. 2268, 2019. 